\title{
Aggressive Behavior, Increased Accumbal Dopamine, and Decreased Cortical Serotonin in Rats
}

\author{
Annemoon M. M. van Erp ${ }^{1}$ and Klaus A. Miczek ${ }^{1,2}$ \\ 1Department of Psychology, Tufts University, Medford, Massachusetts 02155, and 2Departments of Psychiatry, \\ Pharmacology, and Neuroscience, Tufts University, Boston, Massachusetts 02111
}

Dopamine (DA) and serotonin have been implicated in the regulation of aggressive behavior, but it has remained challenging to assess the dynamic changes in these neurotransmitters while aggressive behavior is in progress. The objective of this study was to learn about ongoing monoamine activity in corticolimbic areas during aggressive confrontations in rats. Male Long-Evans rats were implanted with a microdialysis probe aimed at the nucleus accumbens (NAC) or medial prefrontal cortex (PFC); next, 10 min samples were collected before, during, and after a 10 min confrontation. Rats continued to display aggressive behavior while being sampled, and they performed two to six attack bites as well as 140 sec of aggressive acts and postures. Dopamine levels in NAC were significantly increased up to 60 min after the confrontation. Peak levels of $140 \%$ were achieved 20-30 min after the confrontation. No concurrent changes in accumbal serotonin levels were seen during or after the confrontation. Dopamine and serotonin levels in PFC changed in the opposite direction, with a sustained decrease in serotonin to $80 \%$ of baseline levels during and after the confrontation and an increase in dopamine to $120 \%$ after the confrontation. The temporal pattern of monoamine changes, which followed rather than preceded the confrontation, points to a significant role of accumbal and cortical DA and 5-hydroxytryptamine in the consequences as opposed to the triggering of aggressive acts. The increase in accumbal DA in aggressive animals supports the hypothesis that this neural system is linked to the execution of biologically salient and demanding behavior.

Key words: aggression; dopamine; serotonin; nucleus accumbens; prefrontal cortex; rats; microdialysis; behavior
The proposal of a deficit in brain serotonin [5-hydroxytryptamine $(5-\mathrm{HT})]$ as a trait marker for violence-prone individuals is based on measurements that are divorced from the actual behavioral event (Mann et al., 1995; Mann, 1999). In such individuals, low levels of the serotonin metabolite 5-hydroxyindoleacetic acid (5-HIAA) were measured in CSF compared with nonviolent controls (Brown et al., 1982; Linnoila et al., 1983; Kruesi et al., 1990; Coccaro, 1992; Virkkunen et al., 1996; Kavoussi et al., 1997). In juvenile monkeys, low levels of 5-HIAA are correlated with increased risk-taking and impulsivity (Higley et al., 1992, 1996; Mehlman et al., 1994). If 5-HT undergoes dynamic state changes (Jacobs and Fornal, 1999) then in vivo measures would indicate whether altered serotonin actually is linked to the occurrence of episodes of aggression.

In rodents, aggressive behavior is effectively reduced by treatment with $5-\mathrm{HT}_{1 \mathrm{~A}}$ and $5-\mathrm{HT}_{1 \mathrm{~B}}$ receptor agonists (Olivier and Mos, 1986; Olivier et al., 1987; De Almeida and Lucion, 1997; Miczek et al., 1998; Simon et al., 1998; de Boer et al., 1999; Ferris et al., 1999; Fish et al., 1999). Furthermore, aggression is increased in $5-\mathrm{HT}_{1 \mathrm{~B}}$ receptor knock-out mice (Saudou et al., 1994). 5-HT modulates aggressive behavior in interaction with other neurotransmitters, of which corticolimbic dopamine (DA) continues to be of interest for its critical role in integrating motivation and motor functions (Robbins et al., 1989).

Damage to or pharmacological inhibition of the prefrontal cortex (PFC) can increase aggression, and this effect is hypothesized to be caused by loss of impulse control (Tobin and Logue, 1994). 5-HT receptor binding data from violent suicide victims point to the PFC as a prime area of interest (Pihl et al., 1995; Mann, 1999). Feedback from PFC and innervation from mesencephalic structures establish the nucleus accumbens (NAC) as a critical part of the circuit (Robbins et al., 1989). Dopamine levels in NAC increase during

Received Aug. 17, 2000; revised Sept. 28, 2000; accepted Oct. 3, 2000

This work was supported by National Institutes of Health Grants DA02632 and AA02155 (to K.A.M). We thank Dr. Cees van Valkenburg for his advice on neurotransmitter measurement in small samples.

Correspondence should be addressed to: Dr. Klaus A. Miczek, Bacon Hall, 530 Boston Avenue, Medford, MA 02155. E-mail: kmiczek@tufts.edu.

Copyright (C) 2000 Society for Neuroscience $0270-6474 / 00 / 209320-06 \$ 15.00 / 0$ positively reinforced behavior, such as drug-taking (Pettit and Justice, 1991; Weiss et al., 1992; Wise et al., 1995; Ranaldi et al., 1999), food-reinforced behavior (Hernandez and Hoebel, 1988), or sexual behavior (Pfaus et al., 1990; Hull et al., 1993), as well as stressful events such as mild footshock (Abercrombie et al., 1989; Sorg and Kalivas, 1991; Imperato et al., 1992) or social defeat (Tidey and Miczek, 1996). Similar dopamine changes are expected during aggressive behavior because of its stressful, motorically demanding, and even rewarding aspects (to the winner of the confrontation).

In the present experiments, we assessed the dynamic changes in DA and 5-HT in the brains of animals during ongoing aggressive behavior, using in vivo microdialysis. The present protocol attempted to differentiate the relative importance of (1) cortical versus accumbal terminals and (2) dopaminergic versus serotonergic activity in a sample of rats with a history of repeated displays of aggressive behavior.

\section{MATERIALS AND METHODS}

Subjects. Male Long-Evans rats (Charles River, Wilmington, MA), weighing 350-375 gm at the start, were each housed with a female in a large stainless steel cage $(70 \times 45 \times 45 \mathrm{~cm})$ with sawdust bedding and a clear polycarbonate front panel. The cages were equipped with a wooden structure to provide cover and gnawing material. The female rats' fallopian tubes were ligated under ketamine $(100 \mathrm{mg} / \mathrm{kg})$ and xylazine $(9 \mathrm{mg} / \mathrm{kg})$ anesthesia to prevent changes in behavior because of the presence of pups. Food and water were available ad libitum. The cages were kept in a temperature-controlled $\left(20-21^{\circ} \mathrm{C}\right)$ and humidity-controlled $(40-50 \%)$ vivarium under a reversed light cycle (lights on between 8:00 P.M. and 8:00 A.M.). During the $1 \mathrm{~d}$ microdialysis experiment, a divider was lowered to restrict access to the front half of the cage $(35 \times 45 \times 45 \mathrm{~cm})$, which was adapted with a sliding roof with a hole for the microdialysis tubing. All procedures were reviewed and approved by the Tufts University Animal Care and Use Committee, following the principles of the National Institutes of Health Guide for the Care and Use of Laboratory Animals.

Resident-intruder confrontations. Three weeks after being housed with a female, the male resident rats confronted a naive male intruder rat $(250-$ $300 \mathrm{gm}$ ) for $5 \mathrm{~min}$, as described previously (Miczek, 1979). In brief, the female rat was removed from the resident's cage for the duration of the confrontation. The confrontations were terminated 5 min after the first attack bite by the resident, after 20 bites, or after $5 \mathrm{~min}$ if no attack occurred. Typically, the resident displays a species-specific pattern of 
Table 1. Aggressive behavior before and during microdialysis testing

\begin{tabular}{lllll} 
Aggression test & $n$ & Attack latency & Bite frequency & Aggressive duration \\
\hline Pretest 1 & 29 & $200(21)$ & $7.7(1.0)$ & n.m. \\
Pretest 2 & 31 & $120(14)$ & $8.3(1.1)$ & n.m. \\
NAC & 18 & $148(38)$ & $3.1(0.8)$ & $151(26)$ \\
PFC & 15 & $155(27)$ & $2.4(0.5)$ & $106(18)$
\end{tabular}

Resident males confronted a smaller male intruder in their home cage for 5 min (premicrodialysis tests) or 10 min (microdialysis tests). The frequency of attack bites, latency to the first attack, and total duration of aggressive acts and postures are listed, with latencies and durations given in seconds. Aggressive behavior during microdialysis is presented for the NAC and PFC subgroups. Note that the NAC group contained animals with bilateral implantations, which were sampled on two separate occasions. Data are expressed as averages \pm SEM. n.m., Not measured.

aggressive behavior, consisting of pursuits, threats, and attacks. Latency to the first attack and total number of attack bites were monitored. The resident rats showed consistent attack behavior resulting in defeat of the intruder, as defined by the intruder showing a supine posture for at least 5 consecutive seconds and emitting $20-30 \mathrm{kHz}$ ultrasonic vocalizations. This initial intruder confrontation was repeated two times with at least $1 \mathrm{~d}$ between tests.

Surgery. Seventeen animals were implanted bilaterally with a CMA/12 guide cannula (CMA Microdialysis, Chelmsford, MA) aimed $2 \mathrm{~mm}$ above the NAC. Nineteen animals were implanted unilaterally with a guide cannula aimed $3 \mathrm{~mm}$ above the PFC. Coordinates were anteroposterior $(\mathrm{AP})+2.0$, mediolateral $(\mathrm{ML}) \pm 1.5$, and dorsoventral (DV) -6.0 from bregma (for NAC) and AP +2.7, ML \pm 0.7 , and DV -2.5 (for PFC), according to Paxinos and Watson (1997). The head-mount was adapted for social interaction tests by adding metal eyelets on either side, allowing for a sturdy connection between the head-mount and the protective wire spring around the microdialysis tubing. After 1 week of recovery, a CMA/12 microdialysis probe $(800 \mu \mathrm{m}$ outer diameter $)$ was lowered into the target area under isoflurane inhalation anesthesia, with a $2 \mathrm{~mm}$ exposed membrane in NAC and a $3 \mathrm{~mm}$ exposed membrane in PFC. The probe was perfused with artificial CSF (in mM: $147 \mathrm{NaCl}, 1.3 \mathrm{CaCl}_{2}, 0.9$ $\mathrm{MgCl}_{2}$, and $4.0 \mathrm{KCl}, \mathrm{pH} 6.5-7.0$ ) at a rate of $0.5 \mu \mathrm{l} / \mathrm{min}$ overnight and 1.0 $\mu \mathrm{l} / \mathrm{min}$ during the experiment, using a CMA/100 pump. A swivel arm (Med Associates, Georgia, VT), a dual-channel swivel (Instech, Plymouth Meeting, PA), and a $45 \mathrm{~cm}$ spring wire protecting the microdialysis tubing (fluorinated ethylene polymer tubing; CMA Microdialysis) allowed free movement of the animal.

Microdialysis protocol. After insertion of the probe, the animal was housed singly overnight for $\sim 16 \mathrm{hr}$ in its modified home cage to allow for neurotransmitters and behavior to reach a stable baseline. On the experimental day, the pump flow was doubled to $1.0 \mu \mathrm{l} / \mathrm{min}$. After $30 \mathrm{~min}$ of stabilization, $10 \mu \mathrm{l}$ samples were collected every $10 \mathrm{~min}$ in a vial containing $5 \mu \mathrm{l}$ of a stabilizing agent (i.e., $1 \%$ ethanol, $0.02 \%$ EDTA) using a nonrefrigerated fraction collector (CMA 142). Samples were stored in a $-70^{\circ} \mathrm{C}$ freezer until analysis. Samples were collected for $50 \mathrm{~min}$ before a 10 min social confrontation and for $80 \mathrm{~min}$ afterward. The social confrontation consisted of the introduction of an experimentally naive intruder rat into the resident's cage, as described above. The intruder was removed after $10 \mathrm{~min}$, corresponding to collection of one sample. Behavior was recorded on videotape during the entire confrontation. In 17 animals with bilateral cannula implantation, a second experiment was performed 1 week after the first experiment to sample the other hemisphere.

HPLC. Samples were analyzed for DA and 5-HT using an LC10-AD pump (Shimadzu, Columbia, MD), a manual injector (model 7125; Rheodyne, Cotati, CA) with a $5 \mu$ l sample loop, a microbore column $(800 \mu \mathrm{m} \times$ $5 \mathrm{~cm}$ ) with $3 \mu \mathrm{m}$ C18 particles (LC Packings, San Francisco, CA), a Decade electrochemical detector (Antec Leyden, Zoeterwoude, The Netherlands), and a data collection and analysis software package (Bioanalytical Systems, West Lafayette, IN). Mobile phase consisting of $25 \mathrm{~mm} \mathrm{NaH}_{2} \mathrm{PO}_{4}, 50 \mathrm{~mm}$ sodium citrate, $27 \mu \mathrm{M} \mathrm{Na}{ }_{2}$ EDTA, and $2.2 \mathrm{~mm} 1$-octanesulfonic acid, $7 \%$ $\mathrm{MeOH}, \mathrm{pH} 4.2$, was pumped at a flow rate of $30 \mu \mathrm{l} / \mathrm{min}$. Retention times for the monoamines were verified daily using a standard solution containing DA, 5-HT, DOPAC, homovanillic acid, and 5-HIAA. Samples were compared using peak heights for DA and 5-HT. Because of their much larger concentration in the samples, the metabolites were not analyzed.

Behavioral analysis. Behavior was recorded on videotape for $5 \mathrm{~min}$ at 30 $\mathrm{min}$ before the confrontation, for the entire $10 \mathrm{~min}$ confrontation, and for 5 min at $60 \mathrm{~min}$ after the confrontation. Behavioral responses were analyzed using customized software (Tufts University data acquisition program) (Miczek, 1982). The following nonsocial behavioral elements were recorded: walking, rearing, digging, self-grooming, inactivity, lying, eating, and drinking. The following social and aggressive behavioral elements were recorded: nasal contact, anogenital contact, allogrooming, attack biting, aggressive posture, sideways threat, dragging, and chasing (Miczek, 1979, 1982). Frequency and duration of behavioral acts and postures were analyzed for each animal. The duration of aggressive behavior was calculated by combining the durations for aggressive posture, sideways threat, and chasing.

Data analysis and statistics. Dopamine and serotonin baseline levels in individuals were calculated by averaging the baseline samples collected preceding the aggressive confrontation. Neurotransmitter levels during and after the confrontation were expressed as percent baseline for each individual. A one-way repeated measures ANOVA was performed for each data set, followed by planned paired $t$ tests comparing baseline with each time point during and after the confrontation. Because of difficulties with keeping probes in place while animals were fighting, the total number of animals differs for each group (see Results). Three animals that stopped displaying aggressive behavior after surgery were excluded from further analysis, and two animals were excluded on the basis of improper probe placement.

\section{RESULTS}

\section{Aggressive behavior}

In the first confrontation with an intruder, conducted before the start of the microdialysis experiment, resident rats attacked on 29 of 36 occasions; in the second test, resident rats attacked on 31 of 36 occasions. The average attack bite frequency was 7.7 in the first test and 8.3 in the second test, and average latency to first attack decreased from 200 to $120 \mathrm{sec}$ (Table 1).

On the experimental day, animals were connected to a wire spring and swivel arm to allow free movement during sampling. Under these tethered conditions, the average attack bite frequency decreased to 3.0 with a latency of $150 \mathrm{sec}$ to the first attack and an average duration of aggressive acts and postures of 100-150 sec (Table 1). There were no significant differences in the level of aggression displayed during microdialysis between animals with probes in the NAC or PFC. Aggressive behavior in the tethered residents consisted mostly of threats and bites, followed by pinning down the opponent into a supine posture, assuming the aggressive posture, and some chasing if the opponent tried to escape. The restrictions of the microdialysis connections prevented roll-andtumble fights. An overview of all aggressive acts and other acts and postures before, during, and after the confrontation is presented in Table 2. All animals were motorically more active during the intruder confrontation, as shown by increased walking, rearing, and grooming, compared with the periods before and after the confrontation. Approximately half the time of the confrontation was spent in interactions with the intruder, in part investigative (i.e., nasal contact, anogenital contact, and allogrooming) and in part aggressive. Approximately 1-2 min were spent in salient aggressive acts, such as aggressive posture and sideways threat.

\section{Microdialysis}

NAC septi

Seventeen rats were bilaterally implanted with guide cannulas aimed at the NAC septi. Because of technical problems, data were collected from 21 microdialysis probes. One case was excluded because of improper placement (Fig. 1), and two animals were excluded because of a lack of aggression after surgery. Dopamine levels in NAC significantly increased after the termination of the aggressive encounter (Fig. 2A) (one-way repeated measures ANOVA; $F=3.89 ; p<0.001)$. The increase reached its peak 20-30 min after the confrontation and remained significantly elevated afterward. Serotonin levels in NAC (Fig. $2 A$ ) were not changed significantly (one-way repeated measures ANOVA; $F=$ 1.36; $p=0.213$ ). 
Table 2. Duration of aggressive and nonaggressive acts and postures during microdialysis

\begin{tabular}{|c|c|c|c|c|c|c|}
\hline & \multicolumn{3}{|c|}{ Nucleus accumbens $(n=18)$} & \multicolumn{3}{|c|}{ Prefrontal cortex $(n=15)$} \\
\hline & Before & Confrontation & After & Before & Confrontation & After \\
\hline Rearing & $14.4(7.0)$ & $31.2(5.9)$ & $6.2(3.9)$ & $0.8(0.6)$ & $35.3(7.6)$ & $3.1(1.6)$ \\
\hline Walking & $6.3(2.4)$ & $53.9(3.9)$ & $6.3(2.5)$ & $1.2(1.1)$ & $47.7(4.4)$ & $5.2(1.8)$ \\
\hline Self-grooming & $29.1(13.0)$ & $55.6(17.1)$ & $34.5(14.6)$ & $25.3(14.1)$ & $43.0(9.6)$ & $8.4(3.7)$ \\
\hline Digging & $3.7(1.8)$ & $0.6(0.5)$ & $0.4(0.2)$ & $0.4(0.4)$ & $0.6(0.3)$ & $0.7(0.6)$ \\
\hline Inactive sitting & $146.3(31.4)$ & $130.2(19.9)$ & $120.0(29.7)$ & $186.8(33.9)$ & $235.4(26.0)$ & $191.4(26.8)$ \\
\hline Lying & $68.5(25.1)$ & $7.1(7.1)$ & $106.0(33.4)$ & $53.1(29.3)$ & $2.5(1.9)$ & $22.7(16.9)$ \\
\hline Nasal contact & $\mathrm{n} / \mathrm{a}$ & $72.1(8.4)$ & $\mathrm{n} / \mathrm{a}$ & $\mathrm{n} / \mathrm{a}$ & $66.6(8.2)$ & $\mathrm{n} / \mathrm{a}$ \\
\hline Allogrooming & $\mathrm{n} / \mathrm{a}$ & $28.2(5.5)$ & $\mathrm{n} / \mathrm{a}$ & $\mathrm{n} / \mathrm{a}$ & $24.6(4.2)$ & $\mathrm{n} / \mathrm{a}$ \\
\hline Anogenital contact & $\mathrm{n} / \mathrm{a}$ & $37.5(5.1)$ & $\mathrm{n} / \mathrm{a}$ & $\mathrm{n} / \mathrm{a}$ & $19.4(3.4)$ & $\mathrm{n} / \mathrm{a}$ \\
\hline Aggressive posture & $\mathrm{n} / \mathrm{a}$ & $57.8(18.3)$ & $\mathrm{n} / \mathrm{a}$ & $\mathrm{n} / \mathrm{a}$ & $26.9(7.0)$ & $\mathrm{n} / \mathrm{a}$ \\
\hline Sideways threat & $\mathrm{n} / \mathrm{a}$ & $63.1(15.7)$ & $\mathrm{n} / \mathrm{a}$ & $\mathrm{n} / \mathrm{a}$ & $53.4(13.7)$ & $\mathrm{n} / \mathrm{a}$ \\
\hline Chasing & $\mathrm{n} / \mathrm{a}$ & $1.4(0.8)$ & $\mathrm{n} / \mathrm{a}$ & $\mathrm{n} / \mathrm{a}$ & $0.4(0.2)$ & $\mathrm{n} / \mathrm{a}$ \\
\hline
\end{tabular}

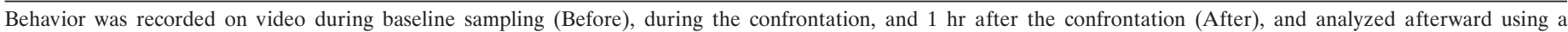
computerized scoring system. All data are durations in seconds and are expressed as averages \pm SEM. For frequency of attacks, see Table 1 . n/a, Not applicable.
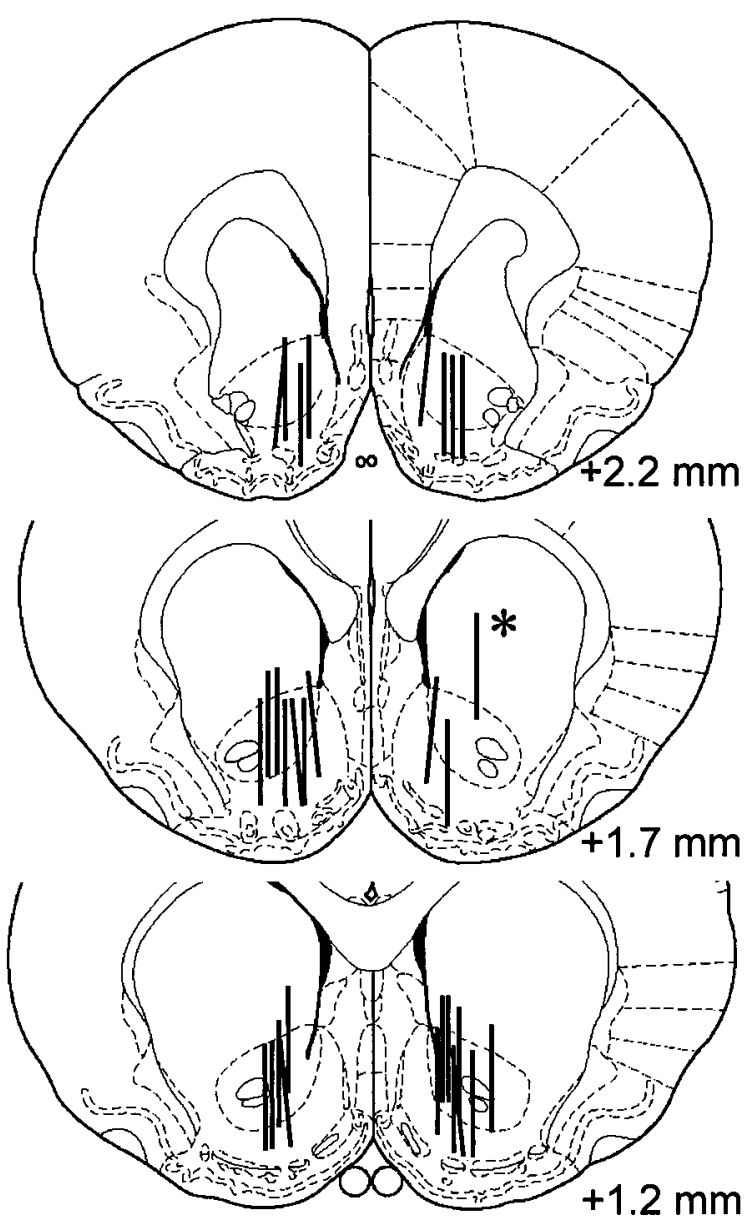

Figure 1. Histological representation of probe placements in NAC. Coronal sections are reproduced from Paxinos and Watson (1997). Vertical bars represent the $2 \mathrm{~mm}$ exposed membrane of each microdialysis probe. Probes were implanted at random in the left or right hemisphere. Asterisks indicate probe placements that were excluded from data analysis.

PFC

Nineteen rats were implanted with a unilateral guide cannula aimed at the PFC. Data were successfully obtained from 17 microdialysis probes. Their placements were confirmed to be in the medial PFC, except for one case (Fig. 3). One animal was excluded because of a lack of aggression after surgery. Cortical serotonin

\section{A. Nucleus accumbens}

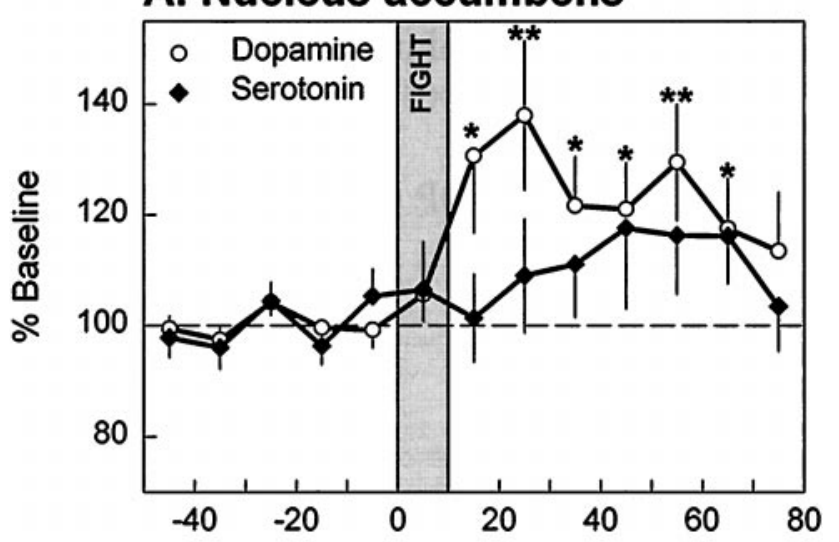

B. Prefrontal cortex

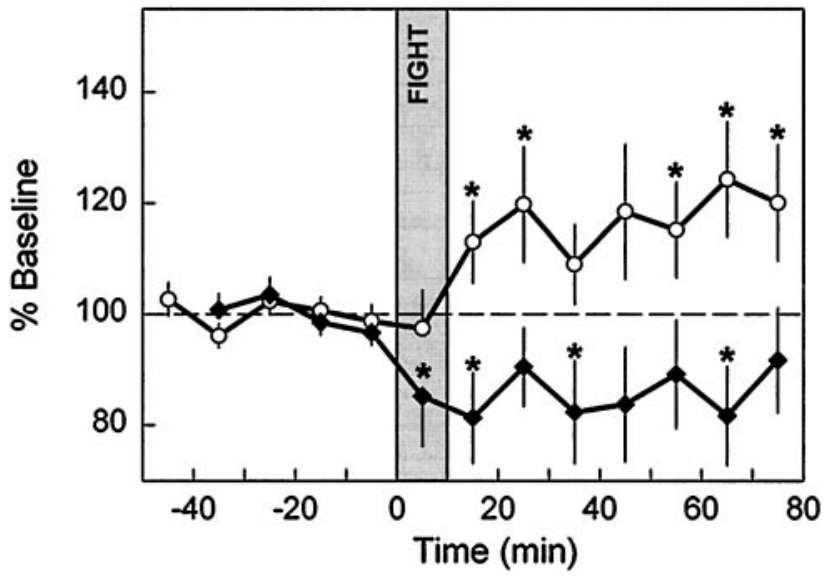

Figure 2. Dopamine and serotonin extracellular concentrations in NAC $(A ; n=18)$ or PFC $(B ; n=15)$ of male resident rats. Ten minute samples were collected $50 \mathrm{~min}$ before, during, and $80 \mathrm{~min}$ after a confrontation with a smaller male intruder. The vertical gray bar indicates the $10 \mathrm{~min}$ period of actual physical confrontation. Filled diamonds, Serotonin; open circles, dopamine. Asterisks indicate a significant change from baseline levels, as assessed by planned paired $t$ tests $\left({ }^{*} p<0.05 ;{ }^{*} p<0.01\right)$.

decreased significantly during and after the confrontation (Fig. 2B) (one-way repeated measures ANOVA; $F=2.070 ; p=0.050$ ). Cortical dopamine, in contrast, increased significantly after the confrontation (one-way repeated measures ANOVA; $F=2.21 ; p=$ $0.025)$. The decline in cortical 5-HT that began during the confrontation persisted for $>1 \mathrm{hr}$ after the confrontation. 


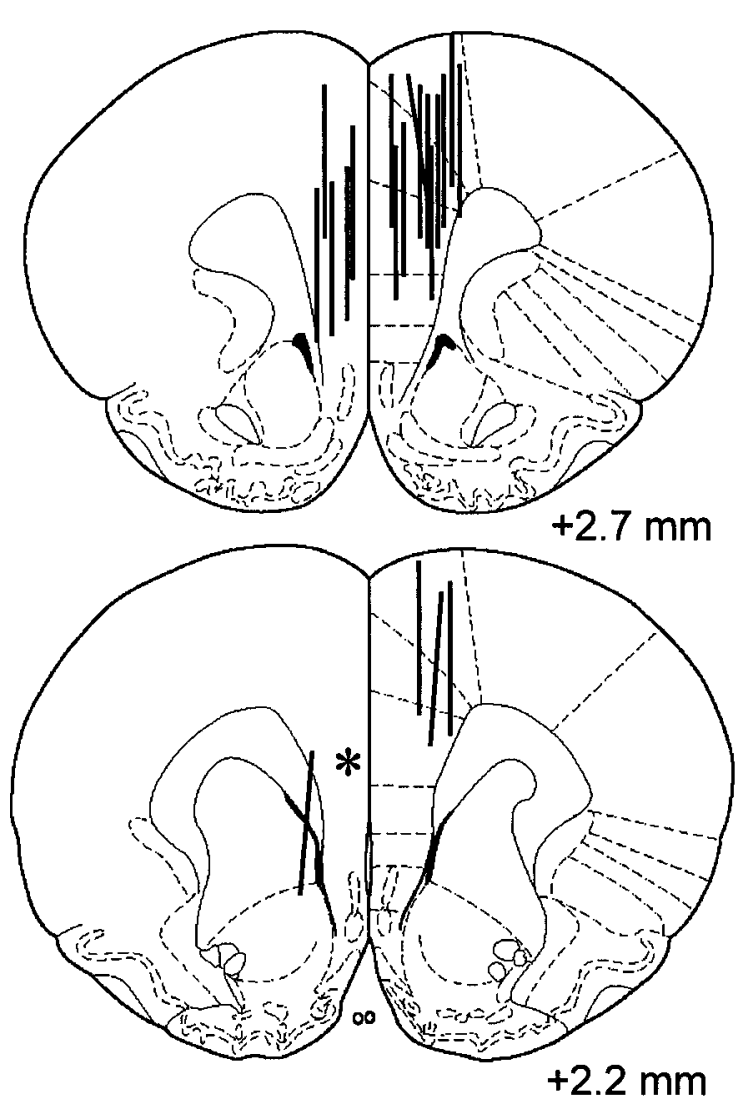

Figure 3. Histological representation of probe placements in PFC. Coronal sections are reproduced from Paxinos and Watson (1997). Vertical bars represent the $3 \mathrm{~mm}$ exposed membrane of each microdialysis probe. See Figure 1.

\section{DISCUSSION}

The current experimental approach enabled the characterization of behavioral and corticolimbic DA and 5-HT activity in association with an aggressive encounter in rats. The data suggest a dissociation between DA and 5-HT activity in NAC and PFC over the course of the aggressive confrontation. First, DA increased in NAC and PFC after the confrontation, whereas accumbal 5-HT remained unaltered. Second, cortical 5-HT decreased during and after the confrontation. Changes in neurotransmitter levels persisted for at least $1 \mathrm{hr}$ after the confrontation.

The dissociation between accumbal and cortical DA and 5-HT activity was also prominent in a parallel study with rats that engaged daily in fighting, at the same time every day for 10 consecutive days. In the absence of the actual fighting behavior on day 11, the aggressive rats showed increased DA immediately preceding the time when they used to start a confrontation with an opponent on previous days, whereas 5-HT decreased thereafter (Ferrari et al., 1998). The dopamine increase is interpreted to reflect behavioral activation in anticipation of the confrontation, and the serotonin decrease may reflect inhibition of aggressive behavior.

The increased DA in NAC and in PFC after aggressive behavior is reminiscent of similar changes in several other significant behavioral contexts. Converging evidence prompts an interpretation of mesocorticolimbic DA as a more integrative system, although the 10-20 min sampling periods for neurotransmitter measurement cannot match the rapid bursts of behavioral acts. For example, increases in accumbal DA have been measured during foraging or the initiation of feeding bouts (Hernandez and Hoebel, 1988; Yoshida et al., 1992; Westerink et al., 1994; Feenstra and Botterblom, 1996) or in the appetitive as well as consummatory phases of copulatory activity (Pfaus et al., 1990; Damsma et al., 1992; Mas et al., 1995; Pfaus et al., 1995; Sato et al., 1995). Importantly, DA changes have been measured after both socially rewarding and aversive events (Mos and van Valkenburg, 1979; Tizabi et al., 1980; Louilot et al., 1986; Haney et al., 1990; Mas et al., 1990). Under the present conditions, dopamine levels increased by $30-40 \%$ above baseline after aggressive episodes, and this increase was approximately half of that measured in defensive rats that were threatened by an aggressive opponent (Tidey and Miczek, 1996). The present data highlight an important role for corticolimbic DA as a consequence of aggressive behavior. These data need to be reconciled with the more common interpretation that cortical and accumbal DA may serve a behaviorally integrating function, enabling patterned acts and postures while attending to communicative signals (Le Moal and Simon, 1991). Further support for this hypothesis is derived from the observation that accumbal DA increased in anticipation of a confrontation (Ferrari et al., 1998).

Methodological issues limit the interpretation of rises in DA, particularly the precise anatomical delineation of the cell groups from which dialysis samples originate, and also the sampling interval across which the measured value integrates. It may be possible to detect much larger increases in DA if the measurements could differentiate between core and shell regions of the NAC, as has been demonstrated with studies on feeding behavior (Kelley, 1999), and if they coincided with the behavioral point event more immediately (Wise et al., 1995). The present study could not accomplish such anatomical precision because of the length of the probes. Our sampling intervals did not allow a differentiation between the rise of DA in NAC versus PFC. Such information would contribute to resolving the proposed functional differentiation between these dopaminergic terminal areas (DiChiara, 1997).

The evidence in support of an inhibitory influence of 5-HT on aggressive behavior derives mainly from assays of CSF or tissue that are separated from the behavior in time, pointing to a trait (Mann et al., 1995; Mann, 1999). Indices of low serotonin activity in the brain have been associated with increased levels of aggression and violent behavior, as measured by decreased 5-HT in brain tissue in aggressive mice (Giacalone et al., 1968; Welch and Welch, 1968; Haney et al., 1990) and by decreased levels of 5-HIAA in CSF in violent humans (Brown et al., 1982; Linnoila et al., 1983; Kruesi et al., 1990; Coccaro, 1992; Virkkunen et al., 1996; Kavoussi et al., 1997) and aggressive macaques (Higley et al., 1992, 1996; Mehlman et al., 1994). Selective serotonergic agonists at the $5-\mathrm{HT}_{1 \mathrm{~A}}$ and $5-\mathrm{HT}_{1 \mathrm{~B}}$ receptor subtypes, as well as serotonin reuptake inhibitors, have been proven very effective in reducing aggressive behavior in rodents and humans (Olivier and Mos, 1986; Olivier et al., 1987; Miczek et al., 1998; de Boer et al., 1999; Ferris et al., 1999; Fish et al., 1999). However, CSF measurements and systemic pharmacological manipulations are removed from the critical neural sites of action. Moreover, these changes are seen in individuals that are at steady-state conditions, long after aggressive acts have taken place, more likely reflecting an aggressive trait rather than the neural dynamics of an aggressive act. The present study showed that acute changes in serotonin levels do occur during and after an aggressive confrontation. It remains challenging to closely match the neurotransmitter sampling scheme to the fastchanging behavioral acts during an aggressive confrontation. Whether these changes occur because of initiation or termination of aggression or because of a general change in behavioral state cannot be determined with the present temporal resolution. The fact that the changes lasted up to $1 \mathrm{hr}$ afterward may rather reflect a change in behavioral state that outlasted the actual execution of the behavior.

The functional significance of corticolimbic serotonin extends from sleep, perceptual processes, and motor control to many appetitive behaviors, including aggressive behavior (Lucki, 1998). The steady basal serotonergic activity recorded in dorsal raphe neurons in cats has been shown to be decreased during sleep and increased with arousal (Jacobs and Fornal, 1999). Supporting data were obtained from microdialysis studies, which showed that various stressful and nonstressful conditions caused a similar increase in extracellular 5-HT in several forebrain sites (Petty et al., 1994; 
Rueter and Jacobs, 1996; Wilkinson et al., 1996). However, the role of 5-HT in stress responses appears to be anatomically differentiated and is not limited to increases. For example, forced swimming caused 5-HT increases in striatum and decreases in amygdala and lateral septum in rats, whereas 5-HT levels in hippocampus and frontal cortex remained unchanged (Kirby et al., 1997). Also, withdrawal after prolonged self-administration of cocaine (a profoundly stressful experience) caused a drop in accumbal serotonin levels (Parsons et al., 1995). Moreover, there is evidence for stressor-specific changes in the frontal cortex, with increased 5-HT after saline injection and decreased 5-HT after forced swimming (Adell et al., 1997). It becomes apparent that precise timing and direction of changes in major terminal areas for serotonin projections depend on the type of stress experience and the relationship to various complex motor and cognitive behaviors. Our finding that serotonin was decreased in PFC but not NAC after aggression adds evidence to this more complex pattern but fails to help resolve the puzzle of stress- and location-dependent changes in serotonin levels. Recent data collected in rats that confronted an opponent for 10 consecutive days at the same time every day show decreased accumbal serotonin on the day after the last confrontation at the time when the confrontation would have taken place previously (Ferrari et al., 1998). These data indicate that serotonin decreases may be associated with anticipation and possibly inhibition rather than direct execution of aggressive behavior. Whether similar 5-HT decreases would occur in PFC needs to be investigated further.

Because individuals that are more prone to aggression may be characterized by a serotonin deficiency, we were interested in determining whether rats that were highly aggressive versus those that were nonaggressive would show differential responses in dopamine or serotonin changes during aggression. Using the present conditions and stock of animals, however, a moderate level of aggression was displayed, and too few animals were highly aggressive (e.g., $>10$ attack bites per 5 min) to allow such a comparison to be made. In addition, marked individual variations in amine changes was observed, which may have occurred in part because of differences in precise anatomical location. Therefore, at present, it remains unclear whether there might have been a correlation between the number of aggressive acts or the duration of aggressive behavior and the magnitude of change in accumbal DA or 5-HT levels. Future studies could address this issue more directly by studying selectively bred rat or mouse lines that show high versus low levels of aggressive behavior (Lewis et al., 1994).

In conclusion, our data support a role for dopamine and serotonin in the consequences of aggressive acts that appear important for the future occurrence of this behavior. Whether these acute changes are correlated with long-term changes in individuals that are more prone to violent episodes remains to be determined. A future task would be to explore strains of high- and low-aggressive animals and to explore both state (i.e., acute 5-HT changes) and trait (i.e., baseline 5-HT and 5-HIAA levels) differences between them.

\section{REFERENCES}

Abercrombie ED, Keefe KA, DiFrischia DS, Zigmond MJ (1989) Differential effect of stress on in vivo dopamine release in striatum, nucleus accumbens, and medial frontal cortex. J Neurochem 52:1655-1658.

Adell A, Casanovas JM, Artigas F (1997) Comparative study in the rat of the actions of different types of stress on the release of 5-HT in raphe nuclei and forebrain areas. Neuropharmacology 36:735-741.

Brown GL, Ebert MH, Goyer PF, Jimerson DC, Klein WJ, Bunney WE, Goodwin FK (1982) Aggression, suicide, and serotonin-relationships to CSF amine metabolites. Am J Psychiatry 139:741-746.

Coccaro EF (1992) Impulsive aggression and central serotonergic system function in humans: an example of a dimensional brain-behavior relationship. Int Clin Psychopharmacol 7:3-12.

Damsma G, Wenkstern D, Pfaus JG, Phillips AG, Fibiger HC (1992) Sexual behavior increases dopamine transmission in the nucleus accumbens and striatum of male rats: comparison with novelty and locomotion. Behav Neurosci 106:181-191.

De Almeida RMM, Lucion AB (1997) 8-OH-DPAT in the median raphe, dorsal periaqueductal gray and corticomedial amygdala nucleus decreases, but in the medial septal area it can increase maternal aggressive behavior in rats. Psychopharmacology 134:392-400. de Boer SF, Lesourd M, Mocaer E, Koolhaas JM (1999) Selective antiaggressive effects of alnespirone in resident-intruder tests are mediated via 5-hydroxytryptamine1A receptors: a comparative pharmacological study with 8-hydroxy-2-dipropylaminotetralin, ipsapirone, buspirone, eltoprazine, and WAY-100635. J Pharmacol Exp Ther 288:1125-1133.

DiChiara G (1997) Cortical and limbic dopamine (on opiate addiction): do not mix before use! Trends Pharmacol Sci 18:77-78.

Feenstra MGP, Botterblom MHA (1996) Rapid sampling of extracellular dopamine in the rat prefrontal cortex during food consumption, handling, and exposure to novelty. Brain Res 742:17-24.

Ferrari PF, van Erp AMM, Tornatzky W, Miczek KA (1998) Recurrent aggressive episodes entrain autonomic activity and dopamine release in n. accumbens. Soc Neurosci Abstr 24:277.

Ferris CF, Stolberg T, Delville Y (1999) Serotonin regulation of aggressive behavior in male golden hamsters (Mesocricetus auratus). Behav Neurosci 113:804-815.

Fish E, Faccidomo S, Miczek KA (1999) Aggression heightened by alcohol or social instigation in mice: reduction by the 5-HT1B receptor agonist CP-94,253. Psychopharmacology 146:391-399.

Giacalone E, Tansella M, Valzelli L, Garattini S (1968) Brain serotonin metabolism in isolated aggressive mice. Biochem Pharmacol 17:1315-1327.

Haney M, Noda K, Kream R, Miczek KA (1990) Regional serotonin and dopamine activity: sensitivity to amphetamine and aggressive behavior in mice. Aggress Behav 16:259-270.

Hernandez L, Hoebel BG (1988) Food reward and cocaine increase extracellular dopamine in the nucleus accumbens as measured by microdialysis. Life Sci 42:1705-1712.

Higley JD, Mehlman PT, Taub DM, Higley SB, Suomi SJ, Vickers JH, Linnoila M (1992) Cerebrospinal fluid monoamine and adrenal correlates of aggression in free-ranging rhesus monkeys. Arch Gen Psychiatry 49:436-441.

Higley JD, Mehlman PT, Poland RE, Taub DM, Vickers J, Suomi SJ, Linnoila M (1996) CSF testosterone and 5-HIAA correlate with different types of aggressive behaviors. Biol Psychiatry 40:1067-1082.

Hull EM, Eaton RC, Moses J, Lorrain D (1993) Copulation increases dopamine activity in the medial preoptic area of male rats. Life Sci 52:935-940.

Imperato A, Angelucci L, Casolini P, Zocchi A, Puglisi-Allegra S (1992) Repeated stressful experiences differently affect limbic dopamine release during and following stress. Brain Res 577:194-199.

Jacobs BL, Fornal CA (1999) Activity of serotonergic neurons in behaving animals. Neuropsychopharmacology 21:9S-15S

Kavoussi R, Armstead P, Coccaro E (1997) The neurobiology of impulsive aggression. Psychiatr Clin North Am 20:395-403.

Kelley AE (1999) Neural integrative activities of nucleus accumbens subregions in relation to learning and motivation. Psychobiology 27:198-213.

Kirby L, Chou-Green J, Davis K, Lucki I (1997) The effects of different stressors on extracellular 5-hydroxytryptamine and 5-hydroxyindoleacetic acid. Brain Res 760:218-230.

Kruesi MJP, Rapoport JL, Hamburger S, Hibbs E, Potter WZ, Lenane M, Brown GR (1990) Cerebrospinal fluid monoamine metabolites, aggression, and impulsivity in disruptive behavior disorders of children and adolescents. Arch Gen Psychiatry 47:419-426.

Le Moal M, Simon H (1991) Mesocorticolimbic dopaminergic network: functional and regulatory roles. Physiol Rev 71:155-234.

Lewis MH, Gariepy JL, Gendreau P, Nichols DE, Mailman RB (1994) Social reactivity and D1 dopamine receptors: studies in mice selectively bred for high and low levels of aggression. Neuropsychopharmacology 10:115-122.

Linnoila M, Virkkunen M, Scheinin M, Nuutila A, Rimon R, Goodwin FK (1983) Low cerebrospinal fluid 5-hydroxyindoleacetic acid concentration differentiates impulsive from nonimpulsive violent behavior. Life Sci 33:2609-2614.

Louilot A, Le Moal M, Simon H (1986) Differential reactivity of dopaminergic neurons in the nucleus accumbens in response to different behavioral situations: an in vivo voltammetric study in free moving rats. Brain Res 397:395-400.

Lucki I (1998) The spectrum of behaviors influenced by serotonin. Biol Psychiatry 44:151-162.

Mann JJ (1999) Role of the serotonergic system in the pathogenesis of major depression and suicidal behavior. Neuropsychopharmacology 21:99S-105S.

Mann JJ, McBride PA, Malone KM, DeMeo M, Keilp J (1995) Blunted serotonergic responsivity in depressed inpatients. Neuropsychopharmacology 13:53-64.

Mas M, Gonzalez-Mora JL, Louilot A, Sole C, Guadalupe T (1990) Increased dopamine release in the nucleus accumbens of copulating male rats as evidenced by in vivo voltammetry. Neurosci Lett 110:303-308.

Mas M, Fumero B, Gonzalezmora JL (1995) Voltammetric and microdialysis monitoring of brain monoamine neurotransmitter release during sociosexual interactions. Behav Brain Res 71:69-79.

Mehlman PT, Higley JD, Faucher I, Lilly AA, Taub DM, Vickers J, Suomi SJ, Linnoila M (1994) Low CSF 5-HIAA concentrations and severe aggression and impaired impulse control in nonhuman primates. Am J Psychiatry 151:1485-1491.

Miczek KA (1979) A new test for aggression in rats without aversive 
stimulation: differential effects of $d$-amphetamine and cocaine. Psychopharmacology 60:253-259.

Miczek KA (1982) Ethological analysis of drug action on aggression, defense, and defeat. In: Behavioral models and the analysis of drug action (Spiegelstein MY, Levy A, eds), pp 225-239. Amsterdam: Elsevier.

Miczek KA, Hussain S, Faccidomo S (1998) Alcohol-heightened aggression in mice: attenuation by $5-\mathrm{HT}_{1 \mathrm{~A}}$ receptor agonists. Psychopharmacology 139:160-168.

Mos J, van Valkenburg CFM (1979) Specific effect on social stress and aggression on regional dopamine metabolism in rat brain. Neurosci Lett 15:325-327.

Olivier B, Mos J (1986) Serenics and aggression. Stress Med 2:197-209.

Olivier B, Mos J, van der Heyden J, Schipper J, Tulp M, Berkelmans B, Bevan P (1987) Serotonergic modulation of agonistic behaviour. In: Ethopharmacology of agonistic behaviour in animals and humans (Olivier B, Mos J, Brain PF, eds), pp 162-186. Dordrecht, The Netherlands: Martinus Nijhoff.

Parsons LH, Koob GF, Weiss F (1995) Serotonin dysfunction in the nucleus accumbens of rats during withdrawal after unlimited access to intravenous cocaine. J Pharmacol Exp Ther 274:1182-1191.

Paxinos G, Watson C (1997) The rat brain in stereotaxic coordinates, Ed 3. San Diego: Academic.

Pettit HO, Justice JB (1991) Effect of dose on cocaine self-administration behavior and dopamine levels in the nucleus accumbens. Brain Res 539:94-102.

Petty F, Kramer G, Wilson L, Jordan S (1994) In vivo serotonin release and learned helplessness. Psychiatry Res 52:285-293.

Pfaus JG, Damsma G, Nomikos GG, Wenkstern DG, Blaha CD, Phillips AG, Fibiger HC (1990) Sexual behavior enhances central dopamine transmission in the male rat. Brain Res 530:345-348.

Pfaus JG, Damsma G, Wenkstern D, Fibiger HC (1995) Sexual activity increases dopamine transmission in the nucleus accumbens and striatum of female rats. Brain Res 693:21-30.

Pihl RO, Young SN, Harden P, Plotnick S, Chamberlain B, Ervin FR (1995) Acute effect of altered tryptophan levels and alcohol on aggression in normal human males. Psychopharmacology 119:353-360.

Ranaldi R, Pocock D, Zereik R, Wise RA (1999) Dopamine fluctuations in the nucleus accumbens during maintenance, extinction, and reinstatement of intravenous $d$-amphetamine self-administration. J Neurosci 19:4102-4109.

Robbins TW, Cador M, Taylor JR, Everitt BJ (1989) Limbic-striatal interactions in reward-related processes. Neurosci Biobehav Rev 13:155-162.

Rueter LE, Jacobs BL (1996) A microdialysis examination of serotonin release in the rat forebrain induced by behavioral/environmental manipulations. Brain Res 739:57-69.

Sato Y, Wada H, Horita H, Suzuki N, Shibuya A, Adachi H, Kato R,
Tsukamoto T, Kumamoto Y (1995) Dopamine release in the medial preoptic area during male copulatory behavior in rats. Brain Res 692:66-70.

Saudou F, Amara DA, Dierich A, LeMeur M, Ramboz S, Segu L, Buhot MC, Hen R (1994) Enhanced aggressive behavior in mice lacking 5-HT1B receptor. Science 265:1875-1878.

Simon NG, Cologer-Clifford A, Lu SF, McKenna SE, Hu S (1998) Testosterone and its metabolites modulate $5-\mathrm{HT}_{1 \mathrm{~A}}$ and $5-\mathrm{HT}_{1 \mathrm{~B}}$ agonist effects on intermale aggression. Neurosci Biobehav Rev 23:325-336.

Sorg BA, Kalivas PW (1991) Effects of cocaine and footshock stress on extracellular dopamine levels in the ventral striatum. Brain Res 559:29-36.

Tidey JW, Miczek KA (1996) Social defeat stress selectively alters mesocorticolimbic dopamine release: an in vivo microdialysis study. Brain Res 721:140-149.

Tizabi Y, Massari VJ, Jacobowitz DM (1980) Isolation induced aggression and catecholamine variations in discrete brain areas of the mouse. Brain Res Bull 5:81-86.

Tobin H, Logue AW (1994) Self-control across species (Columba livia, Homo sapiens, and Rattus norvegicus). J Comp Psychol 108:126-133.

Virkkunen M, Goldman D, Linnoila M (1996) Serotonin in alcoholic violent offenders. In: Genetics of criminal and antisocial behaviour (Bock GR, Goode JA, eds), pp 168-177. Chichester, UK: Wiley.

Weiss F, Paulus M, Lorang MT, Koob GF (1992) Increases in extracellular dopamine in the nucleus accumbens by cocaine are inversely related to basal levels: effects of acute and repeated administration. J Neurosci $12: 4372-4380$

Welch AS, Welch BL (1968) Effect of stress and para-chlorophenylalanine upon brain serotonin, 5-hydroxyindoleacetic acid, and catecholamines in grouped and isolated mice. Biochem Pharmacol 17:699-708.

Westerink BHC, Teisman A, Devries JB (1994) Increase in dopamine release from the nucleus accumbens in response to feeding: a model to study interactions between drugs and naturally activated dopaminergic neurons in the rat brain. Naunyn Schmiedebergs Arch Pharmacol 349:230-235.

Wilkinson LS, Humby T, Killcross S, Robbins TW, Everitt BJ (1996) Dissociations in hippocampal 5-hydroxytryptamine release in the rat following pavlovian aversive conditioning to discrete and contextual stimuli. Eur J Neurosci 1996:1479-1487.

Wise RA, Newton P, Leeb K, Burnette B, Pocock D, Justice JBJ (1995) Fluctuations in nucleus accumbens dopamine concentration during intravenous cocaine self-administration in rats. Psychopharmacology 120:10-20.

Yoshida M, Yokoo H, Mizoguchi K, Kawahara H, Tsuda A, Nishikawa T, Tanaka M (1992) Eating and drinking cause increased dopamine release in the nucleus accumbens and ventral tegmental area in the rat: measurement by in vivo microdialysis. Neurosci Lett 139:73-76. 